\title{
The economic perspective of respiratory general practitioners with a special interest (GPwSIs): proceed with caution
}

\section{David Kernick}

I ncentives to shift the balance of care towards the primary sector were first introduced in the 1990 GP Contract, mainly directed by financial incentive. ${ }^{1}$ However, the cost effectiveness of these shifts remained unproven and may even have induced GPs to practice inefficiently. ${ }^{2}$

The latest attempt to reconfigure primary care service delivery is the concept of intermediate care. This development forms part of a modernisation agenda to make services more flexible and accessible. The aim is for primary care organisations (PCOs) to commission clinical services that have historically been delivered in secondary care led by GPs with special interests (GPwSIs) ${ }^{3}$

(www.doh.gov.uk/pricare/gp-specialinterest). This concept has not been without its opponents who argue that GPs are already specialists in family medicine and the essence of general practice would be undermined. $^{4}$

A working party of the General Practice Airways Group and the Royal College of General Practitioners has published a guide for Primary Care Organisations (PCOs) outlining possible roles and core competencies of a GPwSI in respiratory medicine. ${ }^{5}$ Unlike other GPwSI frameworks, it emphasises the importance of service development, education and liaison roles to reflect the local needs of PCOs in addition to clinical competencies. However, in common with GPwSI developments in other areas, there was no consideration of the specific objectives of the service development or the economic issues.

There are a number of inputs into any policy process but against a background of resource scarcity, economic analysis is gaining an increasing importance. This exercise relates health outputs (benefits) of competing interventions to the resources that are consumed in their production ensuring the most efficient utilisation of available resources. In order to undertake an economic exercise, PCO decision-makers must be clear about their objectives. These may include:

- Secondary care service substitution. GPwSIs can substitute for secondary care practitioners either releasing specialist time to enhance care in other areas or reducing specialist manpower requirements. For example, developing GPwSI respiratory clinics.

- Secondary care service addition. i.e. complementing or enhancing existing services. For example, co-ordination and liaison with local secondary care respiratory services.

- Meeting unmet need. For example, education of GPs and nurses or identifying and managing patients who would not have previously consulted.
In addition, the context of the proposed change must be clarified. Service shifts may arise in the context of new resources becoming available, be financed by the withdrawal of existing secondary care resources or a combination of both.

How an economic evaluation is undertaken will depend on the aim and context of the exercise and different answers may be obtained for different situations. For example, if a GPwSI respiratory clinic is an additional service using additional resources with the aim of meeting increased demand, the aim will be to allocate these new resources efficiently. i.e. maximising benefits from the available resources. When services are being substituted, the development should be compared with the service it is replacing. Where it is intended to release existing hospital resources, due to the high fixed cost of secondary care there will have to be a certain threshold size for the new service before resources can actually be released i.e. reduction in secondary care manpower or ward closure.

There will also be practical problems in undertaking economic studies. Not all questions can be addressed in a rigorous manner that is generalisable to the local conditions of each PCO and there are often insurmountable problems capturing accurate costs and relevant outcomes. In addition, most decisions will not be whether services should be totally delegated or not but the degree to which existing services should change. A marginal analysis recognises the importance of how benefits and costs change as programmes expand or contract. ${ }^{6}$ For example, what is the most efficient mix of doctors and nurses to provide intermediate respiratory care? In principle, the relationship between costs and benefits should be determined across a number of options to identify the optimum service pattern but this will rarely be possible.

In summary, the current developments in all sectors of intermediate care are occurring ahead of an any evidence base of cost effectiveness and inevitably, practical and methodological issues will limit any future economic studies. Although the move towards unified PCO budgets may facilitate a broader economic perspective, evidence of efficient use of limited PCO resources will be difficult to obtain. However, when developing intermediate respiratory care, an awareness of basic economic principles will guard against services being introduced that are thought to be efficient when in fact they may not be so.

\section{Dr. David Kernick \\ General Practitioner \\ Correspondence to: St Thomas' Medical Group Cowick Street Exeter EX4 1HJ}

Tel: +44 (0)1392 676673 Fax: +44 (0)1392 676677 E mail: su1838@eclipse.co.uk

Date submitted: 06/10/03 Date accepted: 15/10/03

\section{Funding}

St Thomas' Medical Group is a research practice
Prim Care Resp J 2003; 12(4):108-109 


\section{Editorial}

funded by the NHS Research \& Development Directorate

\section{References}

1.General Practice and the National Health Service: The 1990 Contract. HMSO: London,1989.

2. Scott T, Maynard A. Will the new GP contract lead to cost effective medical practice? Discussion paper 82. Centre for Health Economics, University of York, 1991.

3.Implementing a scheme for General Practitioners with a special interest. Dept of Health and Royal
College of General Practitioners: London, 2002. 4.Shaping tomorrow. British Medical Association London 2002.

5.A working party of the General Practice Airways Group and the Royal College of General Practitioners General practitioners with a special interest in respiratory medicine. Prim Care Resp J 2003;12(2):38-41.

6.Torgerson DJ, Spencer A. Marginal costs and benefits. BMJ 1996;312:35-6. 